\title{
Adult Onset Still's Disease-Diagnosis on a Stand Still
}

Sahil Bhagat ${ }^{*}$ and Vijay Krishna Dhobale

Department of Medicine Pad, Dr. D.Y. Patil Medical College and Research Centre Pune, Maharashtra, India

*Corresponding author: Sahil Bhagat, Dr. DY Patil Medical College and Research Centre Pune, Maharashtra, India, Tel: +91-8698022428; E-mail: drsahilbhagat@yahoo.in

Rec date: Mar 30, 2015 Acc date: Jun 02, 2015 Pub date: Jun 08, 2015

Copyright: (c) 2015 Sahil B. This is an open-access article distributed under the terms of the Creative Commons Attribution License, which permits unrestricted use, distribution, and reproduction in any medium, provided the original author and source are credited.

\section{Abbreviations:}

AOSD: Adult Onset Still's Disease; PUO: Pyrexia of Unknown Origin

\section{Introduction}

Adult-onset Still's disease is a systemic inflammatory disease, named after English physician Sir George Frederic Still (1861-1941) [1]. The classic presentation is the triad of persistent high spiking fever, joint pain and a distinctive salmon-colored rash (appearing typically during fever episodes). The symptoms are similar to other

\begin{tabular}{|l|l|l|}
\hline Major criteria & Minor criteria \\
\hline Fever of at least 39C for at least one week. & Sore throat \\
\hline Arthralgia or arthritis for at least 2 weeks & lymphadenopathy \\
\hline Non pruritic salmon coloured rash (usually over extremities while febrile). & Hepatomegaly or splenomegaly & Abnormal liver function tests \\
\hline Leucocytosis & Negative tests for ANA and RF & \\
\hline
\end{tabular}

Table 1: Eight sets of diagnostic criteria for adult-onset Still's disease.

For diagnosis atleast 5 criteria are required with atleast 2 major. In our case all the major and 3 minor criteria were fulfilled. Though elevated serum ferritin levels is not yet considered as an criteria for diagnosis of AOSD in Yamaguchi criteria but there are several studies which has shown a strong association between extremely high serum ferritin (much higher than seen in any other infectious or autoimmune diseases) and AOSD [11-15] (Table 1).

\section{Case Presentation}

A 40 year female patient came with complaints of fever and joint pains since 1 month. The fever was high grade, intermittent with chills and rigors. It responded to antipyretic medication.

She had pain in multiple joint pains involving both the large and small joints. There was history of muscle aches as well. Patient also complained of rash appearing on the extremities during episodes of fever. There was no history of cough, breathlessness, loose motions, bleeding tendencies, abdominal pain, headache, and discharge from ears or eyes, burning micturition. There was no past history of similar episodes or any other major illness.

The patient consumed mixed diet and did not notice disturbances in sleep pattern. There was no significant medical, social and family history in the past. inflammatory diseases and to autoimmune diseases which do have characteristic antibodies, which must be ruled out with tests for those antibodies.

Prevalence is estimated at 1.5 cases per $100,000-1,000,000$ population with a bimodal age distribution with one peak between 15-25 years and second between 25-36 years [2]. The etiology of adultonset Still's disease is not known, but it presumably involves IL-1, IL-1 $\beta$ and IL-18 [3]. The diagnosis is clinical and not based upon serology. At least eight sets of diagnostic criteria have been devised [4-11], however the Yamaguchi criteria has the highest sensitivity [10].
Lab investigations showed leucocytosis with TLC of 16500/cu mm (predominant polymorphs) Serum ferritin was elevated at $3948 \mathrm{ng} / \mathrm{ml}$ (N R: 10-190). LFT, RFT, Serum Electrolytes, Serum Proteins were normal.

Patient was negative for Dengue IgM/IgG, Brucella IgM, Chikungunya IgM, Rapid Malaria test, Widal test, Weil Felix test, monospot and Paul Bunnell for infectious mononucleosis, VDRL, HIV and HbsAg. Chest X-ray and X-rays of involved joints and ultrasonography of abdomen were normal.

Thyroid function tests were normal. Repeated blood and urine cultures showed no growth.

Patient was RA/ASO negative. Patient was negative for rhematologic antibody panel namely anti-CCP, ANA, nRNP/Sm, SSa, SSb, Ro-52, Scl-70, PM-Scl, Jo-1, CENP-B, PCNA, dsDNA, Antihistone, anti nucleosome, anti-ribosomal-P Protein and AMA-M2.

Skin biopsy was obtained from the lesion of left index finger which was suggestive of marked hyperkratosis, parakerotosis and acanthosis, the central portion showed necrosis of epidermis as well as fragmentation of collagen in superficial dermis and infilteration by neutrophils and eosinophils. The final impression was necrotizing inflammation due to small vessel vasculitis. Lymph node biopsy was done which showed reactive hyperplasia. In view of clinical presentation, lab investigation, negative antibody panel, skin biopsy 
report and markedly elevated serum ferritin levels diagnosis of "Adult Onset Still's Disease" was made.

In view of the clinical presentation and examination findings, the infections and autoimmune disorders were considered as major differentials.

With help of serological tests the probable infections like enteric, brucella, infectious mononucleosis HIV disease and syphilis were ruled out, after which screening for autoimmune collagen vascular disorders was done which was negative.

Exclusion of two major (above mentioned) differentials directed us to proceed towards an alternate diagnosis.

Patient was treated with oral glucocorticoids and NSAIDS which were gradually tapered off and she responded well to the treatment with symptomatic improvement.

\section{Conclusion}

Adult onset still's disease is one of underreported and under diagnosed causes of PUO. Diagnosis is clinical and not based on serology. Extremely high serum ferritin levels is a peculiar characteristic of the disease (though the serum ferritin levels are elevated in many inflammatory, infections and malignant disorders but the levels in adult onset still's disease is much higher when compared to other above mentioned conditions). Hence we recommend serum ferritin levels to be included as diagnostic criteria for Adult onset still's disease.

In a case of PUO, consider adult onset still's disease as an important differential.

\section{Consent}

Written informed consent was obtained from the patient for publication of this case report and accompanying images. A copy of written consent is available for review by Editor-in-Chief of this journal.

\section{Authors Contributions}

$\mathrm{SB}$ and $\mathrm{AK}$ analysed and interpreted the patient data and were the major contributors in writing the manuscript; VG and ZS contributed in analysing, writing and revising the manuscript.

\section{References}

1. GF Still (1896) A special form of joint disease met with in children. Doctoral dissertation, Cambridge.

2. Owlia MB, Mehrpoor G (2009) Adult onset Still's disease: A review. Indian J Med Sci 63: 207-221.

3. Fujii T, Nojima T, Yasuoka H, Satoh S, Nakamura K, et al. (2001) Cytokine and immunogenetic profiles in Japanese patients with adult Still's disease (Association with chronic articular disease). Rheumatology (Oxford) 40: 1398-1404.

4. Cush JJ (2000) Adult onset Still's disease. Bull Rheum Dis 49: 1-4.

5. Calabro JJ, Londino AV (1986) Jr. Adult onset still's disease. J Rheumatology 13: 827-828.

6. Crispin JC, Martinez-Banos D, Alcocer-Varela J (2005) Adult onset still's disease as the cause of fever of unknown origin. Medicine (Baltimore) 84: 331-337.

7. Goldman JA, Beard MR, Casey HL (1980) Acute febrile juvenile rheumatoid arthritis in adults: Cause of polyarthritis and fever. South Med J 73: 555-563.

8. Kahn M, Delaire M (1991) Still del'adulte disease. In: M Kahn, Peltier A, Meyer O, Piette J, editors Systemic diseases, Paris: Flammarion : 231-238.

9. Reginato AJ, Schumacher HR Jr, Baker DG, O'Connor CR, Ferreiros J (1987) Adult onset Still's disease: Experience in 23 patients and literature review with emphasis on organ failure. Semin Arthritis Rheum 17: 39-57.

10. Yamaguchi M, Ohta A, Tsunematsu T, Kasukawa R, Mizushima Y, et al. (1992) Preliminary criteria for classification of adult Still's disease. J Rheumatol 19: 424-430.

11. Fautrel B, Le Moel G, Saint-Marcoux B, Taupin P, Vignes S, et al. (2001) Diagnostic value of ferritin and glycosylated ferritin in adult onset Still's disease. J Rheumatol 28: 322-329.

12. Rau M, schiller M, Krienke S, Heyder P, Lorenz HM, et al. (2010) Clinical manifestations but not cytokine profiles differentiate adult onset Still's disease and sepsis. J Rheumatol 37: 2369-2377.

13. Lian F, Wang Y, Yang X, Xu H, Liang L (2010) Clinical features and hyperferritinemia diagnostic cutoff points for AOSD based on ROC curve: a Chinese experience. Rheumatology International 1-4.

14. Schiller D, Mittermayer H, Hirschmann JV (1998) Hyperferritenemia as a marker of Still's disease. Clinical Infectious Diseases 26: 534-535.

15. Vignes S, Le Moel G, Fautrel B, Wechsler B, Godeau P (2000) Percentage of glycosylated serum ferritin remains low throughout the course of adult onset Still's disease. Annals of the Rheumatic Diseases 59: 347-350. 